\title{
Training EFL Students on Relaxation Techniques to Manage Test Taking Anxiety: An Action Research Project
}

\author{
Manar Dahbi ${ }^{1}$ \\ ${ }^{1}$ Imzouren Secondary School, Morocco \\ Received: December 6, 2014 Accepted: December 29, 2014 Online Published: January 3, 2015 \\ doi:10.5430/ijelt.v2n1p61 URL: http://dx.doi.org/10.5430/ijelt.v2n1p61
}

\begin{abstract}
As a matter of fact, many students cannot perform well under testing conditions. They feel over-anxious as they take tests in general. This action research project was carried out with fifty eight second year baccalaureate students from two classes to assess the relationship between anxiety and academic performance in English written tests. To help students overcome this problem they were trained to use stress management techniques to relieve anxiety before and while taking tests. It was assumed that once students felt relaxed, they would be able to perform better.
\end{abstract}

Keywords: test anxiety, stress management, relaxation techniques, relaxation response

\section{Introduction}

English is a very important school subject for baccalaureate students in Morocco. Getting high marks in the English test means success in one of the core subjects in the final national baccalaureate exam that Moroccan students sit for upon completion of their secondary school education. Therefore, students are anxious to get high scores.

During the first semester I noticed that written tests caused a high degree of anxiety and a sense of failure for students who did not have the skills to cope with test taking stress. During that time, students were observed in both testing and non-testing situations. It seems that most students perform better under non-testing conditions; in a more relaxed and non-threatening environment.

When observing these students taking tests, it was noticed that they moved around in their chairs and showed signs of discomfort. When interviewed about the cause, the students mentioned anxiety as the main factor that prevented them from focusing on the test. In fact, when anxiety and fear take over, it becomes very difficult for these students to perform well. So, I deduced that it was necessary for these students to be trained on stress management techniques to overcome test taking anxiety.

\section{Review of the Literature}

\subsection{Defining Test Anxiety}

According to Kline (2006: 27) learners can be anxious about many things while learning an L2; however, the three main areas of anxiety that have received most attention are verbal communication fear, test anxiety, and fear of negative evaluation.

Cizek\& Burg (2006: 11) define test anxiety as a type of performance anxiety -a feeling someone might have in a situation where performance really counts or when the pressure is on to do well. Sarason (1988: 19) further explains that "Anxiety is a basic human emotion that consists of fear and uncertainty". According to Wadhwa (2008: 213), anxiety has its positive and negative sides. For some students, it motivates them to perform better, but for most, test anxiety may be so great that it interferes with test performance. These are typically students who are generally anxious, and the test simply adds to their already high level of anxiety.

In relation to second language learning, the literature has shown that learning a foreign language causes anxiety and poor language achievement. In this respect, Saito et al. (1999:215) argue that unfamiliar scripts, writing systems, and unfamiliar cultural material cause EFL anxiety. Tittle (1997: 1) adds that foreign and second language students have irrational beliefs that cause anxiety and affect language achievement. 


\subsection{The Major Causes of Test Anxiety}

Cassady (2001: 270) emphasises that all anxiety is a reaction to anticipating something stressful. Focusing on the bad things that could happen fuels test anxiety. For example, someone worrying about doing poorly might have thoughts like: "What if I forget everything I know?" or "What if the test is too hard?" Too many thoughts like these leave no mental space for thinking about the test questions. People with test anxiety can also feel stressed out by their physical reaction and think things like "What if I throw up?" or "Oh no, my hands are shaking." (Cassady op.cit: 271).

MacIntyre et al. (1997: 269) further explain that "anxious language learners may focus their attention on their perceived inadequacies, the potential for failure, and the consequences of that imagined failure, rather than concentrating on the task itself". Just like other types of anxiety, test anxiety can create a vicious circle; the more a person focuses on the bad things that could happen, the stronger the feeling of anxiety becomes. This makes the person feel worse. And because his or her head is full of distracting thoughts, he/she is likely to do poorly on the test.

Cizek\& Burg (op.cit: 54-56) argue that people who worry a lot or who are perfectionists are more likely to have trouble with test anxiety. People with these traits sometimes find it hard to accept mistakes they might make or to get anything less than a perfect score. In this way, even without meaning to, they might really pressure themselves. Students who are not prepared for tests but who care about doing well are also likely to experience test anxiety. According to Cizek\& Burg (op.cit: 56) people can feel unprepared for tests for several reasons: they may not have studied enough, they may find the material difficult, or perhaps they feel tired because they did not get enough sleep the night before.

\subsection{The Main Symptoms of Test Anxiety}

Like other anxiety reactions, test anxiety affects the body and the mind. When people are under stress, the body releases the hormone adrenaline which prepares it for danger. This is referred to as the "fight or flight" reaction. That is what causes some physical symptoms. According to Mcllroy (2005: 74-75) some students experience mainly physical symptoms, such as headaches, nausea, faintness, feeling too hot or too cold, sweating, a pounding heart, and rapid breathing. These sensations might be mild or intense. Others experience more emotional symptoms, such as crying easily, feeling irritable, or getting frustrated quickly. Cassady (op.cit: 270) adds that a major problem of test anxiety can be its effect on thinking ability; it can cause a person to "blank out" or have racing thoughts that are difficult to control. It can also cause poor concentration, confusion, and poor organization. This inability to concentrate impedes performance on tests.

\subsection{Managing Test Anxiety}

Test anxiety is a major obstacle in academic success. What can a learner do to trick the mind into believing that testing is not dangerous?

It has been reported in the literature that many schools that taught students how to apply stress management techniques claimed that "the technique worked so well that test scores soared" (Rozanski 2002: 2). Saito et al. (op.cit: 216) add that student success rates were higher in classrooms of teachers with positive and supportive attitudes before a test. Moreover, Drucker (2003: 3) reported that students did well on tests in ESL/EFL classes where teachers received training in relaxation exercises. Also, Guthrie (2002:5) emphasised that students who received training in relaxation and breathing exercises before tests scored well. The aim of stress management was to break the link between irrelevant stress reactions (diffused attention, fear, etc.), and academic tasks. The main test anxiety managing techniques used included: relaxation techniques, and yoga exercises.

According to Bernstein et al. (2000: 9) the relaxation response is any technique or procedure that helps people become relaxed. It takes the place of an anxiety response. Merell (2008: 171) argues that there are many ways to conduct relaxation training with students and it is important for practitioners to select the method of training that is best suited for the specific students involved in the intervention, and for the particular circumstances under which this intervention takes place. In fact, the mostly reported relaxation techniques that help control test anxiety include: first, the tensing and differential relaxation method which helps relax by first tensing and then relaxing specific muscles. Second, the palming method which is a visualization procedure used to reduce test anxiety. And finally, thought-stopping techniques that assist students who have difficulty stopping their negative self-talk. A Negative self-talk, is defined as the negative statement students tell themselves before and during tests. Examples of negative self talk include "No matter what I do, I will not pass the course." "I cannot remember the answers. I am going to fail this test.", etc. Coon (2005: 559) believes that negative self-talk causes students to lose confidence and give up on tests. These students need to use the thought stopping technique to overcome their worry and become relaxed. This technique consists of changing negative-self talk into positive self-talk statements. Coon (op.cit: 559) suggests that to stop their thoughts before or during a test, students need to silently shout to themselves "Stop" or "Stop thinking about that." After that 
they need to repeat a positive self-talk statement, such as: "I went blank on the last test, but I now know how to reduce test anxiety." "I prepared for this test and will do the best I can.", etc. Using positive self-talk before a test can help reduce test anxiety and improve grades. During tests, positive self-talk can build confidence and decrease test anxiety.

\section{Methodology}

\subsection{Research Questions}

This study seeks to answer the following questions:

-How do EFL students feel about taking a written test in English?

-What can be done to help students overcome anxiety while taking English tests?

\subsection{Participants}

This research project involved two second year baccalaureate arts classes that consisted of fifty eight female students (29 students for each class) assigned to the teacher researcher by the administration of Imzouren secondary school in Imzouren, a village that is eighteen kilometres away from the city of Al-Hoceima in the North of Morocco. Their age ranges from seventeen to nineteen years and they all expressed their willingness to participate in the study.

\subsection{Instrumentation}

At the beginning of the study, students sat for a pre-test. Then, they answered a survey questionnaire that was designed to acquire a better understanding of how the students felt about taking ESL/EFL tests. Based on the results of the survey a plan of action was prepared. It was an eight-week program to teach students how to apply test stress management techniques. At the end of this training-program, the students took a post-test and a questionnaire to document their reactions after implementing the plan of action. The pre and post tests scores were compared.

\section{The Study}

The goal of the study was for a group of second year baccalaureate students to improve their grades on written tests in English. To this end, these students were trained on how to apply relaxation techniques to help them feel confident during English tests and cope with test taking anxiety.

The plan of action took eight weeks. Each of the two groups had to come for a session of two hours a week. In the first two weeks, the students were trained to go through the different steps of the tensing and differential relaxation method. This required students at the beginning to follow these instructions:

1 Put your feet flat on the floor.

2 With your hands, grab underneath the chair.

3 Push down with your feet and pull up on your chair at the same time for about five seconds.

4 Relax for five to ten seconds.

5 Repeat the procedure two or three times.

These instructions were repeated many times until students could master the technique. Then, they were asked to practise the tensing and differential relaxation method alone.

During the second pair of weeks, students learned how to use the palming method. This involved repeating the following instructions many times so that they could become familiar with the technique and apply it by themselves later on:

1 Close and cover your eyes using the center of the palms of your hands.

2 Prevent your hands from touching your eyes by resting the lower parts of your palms on your cheekbones and placing your fingers on your forehead.

3 Think of some real or imaginary relaxing scene. Mentally visualize this scene. Picture the scene as if you were actually there looking through your own eyes.

4 Visualize this relaxing scene for one to two minutes.

During the last two weeks, the students were taught how to apply a thought-stopping technique. The students draw a circle on a paper and wrote in that circle starting from the centre and going outwards in a circular manner, the words: 
"I am getting high marks in the test". The outcome looked like a snail. The students discussed their writing, and how they felt.

At the end of week eight, students sat for a post test. Then, they took a survey questionnaire similar to the first one. The aim was to give the students a chance to express how they felt then in comparison to how they had felt before.

\section{Findings}

At the beginning of the research project a survey was conducted to acquire a better understanding of how students felt about taking ESL tests and to get a wider perspective of the problem. Figures were used to evaluate the questionnaire responses.

A majority of the respondents (65.5 per cent) reported feelings of discomfort when informed that they were going to have a test in English, and wished they could learn without having exams. While waiting for the tests 68.9 per cent of the students felt uncomfortable and had negative thoughts they knew nothing. 17.2 per cent felt they had a stomach-ache, and only 13.7 per cent felt they were going to do well as table 1 demonstrates.

Table 1. Percentages of questions 1 and 2 in the survey before the plan of action

\begin{tabular}{|l|l|l|l|}
\hline Survey questions & Answer "a" & Answer "b" & Answer "c" \\
\hline $\begin{array}{l}\text { 1. How do you feel the moment you find out } \\
\text { that you are going to have a test in English? }\end{array}$ & $13.7 \%$ & $20.6 \%$ & $65.5 \%$ \\
\hline $\begin{array}{l}\text { 2. How do you feel while you are waiting } \\
\text { for the test sheet? }\end{array}$ & $13.7 \%$ & $17.2 \%$ & $68.9 \%$ \\
\hline
\end{tabular}

When asked what thoughts went through their minds during the test, 72.4 per cent mentioned the fear of not having enough time, and $15.5 \%$ had distracting thoughts of failure. 44.8 per cent of the students reported also that such feeling of anxiety prevented them from thinking appropriately while answering questions, and 34.4 per cent could not plan their time and always run out of time to check their work before handing it in.(See table 2)

Table 2. Percentages of questions 3 and 4 in the survey before the plan of action

\begin{tabular}{|l|l|l|l|}
\hline Survey questions & Answer "a" & Answer "b" & Answer "c" \\
\hline $\begin{array}{l}\text { 3. What thoughts go through your mind } \\
\text { during the test? }\end{array}$ & $72.4 \%$ & $12.06 \%$ & $15.5 \%$ \\
\hline $\begin{array}{l}\text { 4. How do you feel while answering the test } \\
\text { questions? }\end{array}$ & $20.6 \%$ & $44.8 \%$ & $34.4 \%$ \\
\hline
\end{tabular}

After the test 53.4 per cent of the students worried about the grade they would receive, 34.4 per cent felt they could have done better and only 12.06 per cent felt fine. Also, 60.3 per cent did not want to share their marks with their classmates, and only 17.2 per cent felt fine. (See table 3).

Table 3. Percentages of items 5and 6 in the survey before the plan of action

\begin{tabular}{|l|l|l|l|}
\hline Survey questions & Answer "a" & Answer "b" & Answer "c" \\
\hline 5. How do you feel after the test? & $34.4 \%$ & $53.4 \%$ & $12.06 \%$ \\
\hline $\begin{array}{l}\text { 6. How do you feel when you get your test } \\
\text { scores? }\end{array}$ & $60.3 \%$ & $17.2 \%$ & $22.4 \%$ \\
\hline
\end{tabular}

In fact, these students felt over anxious about English tests because they realized the importance of English to their future as 81.03 per cent of them believe. The drive to succeed caused them to use ineffective strategies and to score 
low. This lack of direction and skills during tests caused anxiety. This is why 93.1 per cent of them expressed their willingness to learn how to use stress management techniques to control their anxiety while taking English tests and improve their performance. (See table 4)

Table 4. Percentages of items 7 and 8 in the survey before the plan of action

\begin{tabular}{|l|l|l|l|}
\hline Survey questions & Answer "a" & Answer "b" & Answer "c" \\
\hline $\begin{array}{l}\text { 7. Why is it important to do well on tests in } \\
\text { English? }\end{array}$ & $81.03 \%$ & $5.17 \%$ & $13.7 \%$ \\
\hline $\begin{array}{l}\text { 8. Would you like to learn stress management } \\
\text { techniques? }\end{array}$ & $93.1 \%$ & $0 \%$ & $6.8 \%$ \\
\hline
\end{tabular}

The aim of this study was for students to get higher scores after participating in the eight-week implementation program. It was assumed that if students learned how to apply relaxation techniques, they would focus better on the tests. The techniques would provide them with the tools necessary to cope with test taking anxiety and help them score better.

The implementation program achieved what it set out to do. First because a comparison between the pre- and postimplementation survey responses indicated that the students' responses which were almost all negative before the eight-week implementation program became positive as it can be deduces from the results in table 5. A majority of 81.03 per cent of the students reported that they felt rather relaxed during a test of English. Besides, 79.3 per cent of the students were able to focus on the questions and find the answers. (See table 5)

Table 5. percentages of items 1, and 2 in students' survey after the plan of action

\begin{tabular}{|l|l|l|l|}
\hline Survey items & Answer "a" & Answer "b" & Answer "c" \\
\hline 1. I feel relaxed during a test of English. & $81.03 \%$ & $18.9 \%$ & $0 \%$ \\
\hline $\begin{array}{l}\text { 2. I focus on the questions and find } \\
\text { the answers. }\end{array}$ & $79.3 \%$ & $20.6 \%$ & $0 \%$ \\
\hline
\end{tabular}

These findings clearly indicate that anxiety has a negative effect on students' concentration. The results also imply that training students on how to use stress management techniques enhances their ability to control their attention - the ability to ignore distractions and to focus attention more on tasks. In fact, in her cognitive-attention theory of test anxiety, Wine (1982: 207) claimed that the negative influence of test anxiety is due to the fact that test-anxious persons divide their attention between personal variables and variables connected to the task. In contrast, non-test-anxious persons are able to focus their attention more on the task itself.

In fact, Wine (op.cit, p: 207-219) explored the effects of anxiety and concentration on school performance, and has found that stress management techniques have a positive impact on concentration and school work, making it possible for students to focus more on tasks. This leads to better grades. With respect to the present study, most students could score better, too, after implementing the program on stress management and relaxation exercises. A comparison between students' scores in the pre-test and the post-test after the implementation program clearly shows that the performance of a considerable number of students improved (see table 6).

Table 6. Comparison of students' scores before and after the eight-week implementation program

\begin{tabular}{|l|l|l|l|}
\cline { 2 - 4 } \multicolumn{1}{c|}{} & Below average mark & Average mark & Above average mark \\
\hline Students' scores before the implementation program & 35 & 19 & 4 \\
\hline Students' scores after the implementation program & 19 & 26 & 13 \\
\hline
\end{tabular}


All the students without exception reported that they used relaxation exercises and techniques to help them relax while taking the post-test, and as results, the marks of 75.8 per cent of them improved. (See table7)

Table 7. percentages of items 3 and 4 in students' survey after the plan of action

\begin{tabular}{|l|l|l|l|}
\hline Survey questions & Answer "a" & Answer "b" & Answer "c" \\
\hline 3. My marks improved in the post-test. & $75.8 \%$ & $24.1 \%$ & $0 \%$ \\
\hline $\begin{array}{l}\text { 4. I used relaxation techniques to relax when } \\
\text { taking the post-test. }\end{array}$ & $100 \%$ & $0 \%$ & $0 \%$ \\
\hline
\end{tabular}

\section{Implications and Conclusion}

The study indicated the positive impact of test-taking relaxation exercises, as effective and powerful tools in improving student scores, on EFL tests. In fact, over the past three decades, research in second language acquisition has confirmed that language learning is indeed enhanced by attention to affect. Many studies suggested that teachers who created a relaxed classroom atmosphere that encouraged risk-taking were most helpful in alleviating foreign language anxiety and facilitating test taking. This implies that teachers need to conduct surveys to gain insights into how students feel about taking tests and work out a plan of action on the basis of the findings to help their students overcome test taking anxiety.

This also implies that teachers need to have pre-service and/or in-service training workshops on how to implement the different relaxation exercises in their ESL classrooms. They need also to conduct action research projects in their classes.

To sum up, the objective of this investigation was to demonstrate the effect of test anxiety on students' performance in English tests and argue for the need to implement stress management techniques to help students relax and enhance their confidence while taking ESL tests. A comparison between the results of the two questionnaires; before and after the plan of action, demonstrates that the negative attitude student had towards taking English tests changed. They could develop a positive reaction towards tests in English after they had learned the relaxation tools that could help them manage test taking stress. This positive attitude had indeed an effect on their scores; the number of students who could score average or above average marks increased in the post-test in comparison with the results of the pre-test.

\section{References}

Bernstein, D. A., Borkovec, T., \& Hazlett-Stevens, H. (2000). New Directions in Progressive Relaxation Training: A Guidebook for Helping Professionals. Praeger Publishers.

Cassady, J. C. (2001). Anxiety in Schools: the Causes, Consequences, and Solutions for Academic Anxieties. Peter Lang publishing, Inc.

Cizek, G. J., \& Burg, S. (2006). Addressing Test Anxiety in a High-Stakes Environment: Strategies for Classrooms and schools. Corwin Press.

Coon, D. (2005). Psychology: A Modular Approach to Mind and Behavior. Wadsworth.

Drucker, J. M. (2003). The reading teacher. Info Trac One File 57(1), 22-30.

Guthrie, J. (2002). Om Schooling/Schools Reach for yoga to Calm and Collect Students. San Francisco Chronicle.

McIlroy, D. (2005). Exam Success. SAGE Publications.

MacIntyre, P. D., Noels, K. A., \& Clement, R. (1997). Biases in self-ratings of second language proficiency: The role of language anxiety. Language Learning, 47(2), 265-287.

Merrell, K. (2008). Helping Students Overcome Depression and Anxiety: A Practical guide. Guilford Press.

Rozanski, C. (2002). Yoga Instructor's Lessons Getting High Grades; Hollywood School Incorporates Exercises in Classes. South Florida Sun.

Saito, Y., Thomas, G. J., \& Horwitz, E. K. (1999). Foreign language reading anxiety. The Modern Language Journal, 83(2), 202-18.

Sarason, I. G. (1988). Test anxiety, worry, and cognitive interference. In R. Schwarzer (ed.), Self-Related Cognition 
in Anxiety and Motivation. Hillsdale, NJ: Erlbaum.

Tittle, M. (1997). The Effects of Foreign and Second Language Students' Irrational Beliefs and Anxiety on Classroom Achievement. EDRS Reproductions.

Wadhwa, S. (2008). A Hand Book of Measurement and Testing. Sarup \& Sons.

Wine, J. D. (1982). Evaluation anxiety: A cognitive-attentional construct. In H. W. Krohne, \& L. Laux (eds.), Achievement, Stress and Anxiety. Washington, DC: Hemisphere. 